\title{
Health outcomes in acromegaly: depression and anxiety are promising targets for improving reduced quality of life
}

\author{
Victor Jacobus Geraedts ${ }^{1,2}$, Christina Dimopoulou ${ }^{1}$, Matthias Auer ${ }^{1}$, Jochen Schopohl ${ }^{3}$, Günter Karl Stalla ${ }^{1}$ \\ and Caroline Sievers ${ }^{1 *}$
}

1 Max Planck Institute of Psychiatry, Munich, Germany

2 Leiden University Medical Center, Leiden, Netherlands

${ }^{3}$ Medizinische Klinik Innenstadt, Ludwig-Maximilians University, Munich, Germany

Edited by:

Gianluca Tamagno, St. Columcille's

Hospital, Ireland

\section{Reviewed by:}

Giovanni Vitale, Università degli Studi di Milano, Italy

Marek Bolanowski, Wroclaw Medical

University, Poland

\section{*Correspondence:}

Caroline Sievers, Department of

Endocrinology, Max Planck Institute

of Psychiatry, Kraepelinstraße 2-10,

Munich 80804, Germany

e-mail: csievers@mpipsykl.mpg.de
Introduction: Remission criteria of acromegaly are based on biochemical variables, i.e., normalization of increased hormone levels. However, the established reduction in Quality of Life (QoL) is suggested to be independent of biochemical control. The aim of this study was to test which aspects predict QoL best in acromegaly.

Methods/design: This is a prospective cohort study in 80 acromegalic patients, with a cross-sectional and longitudinal part. The main outcome measure was health-related QoL, measured by a generic and a disease-specific questionnaire (the SF-36 and AcroOoL). Main predictors were age, gender, biochemical control, disease characteristics, treatment modalities, and psychopathology.

Results: Our cohort of 80 acromegalics had a mean age $54.7 \pm 12.3$ years with an average disease duration of $10.8 \pm 10.0$ years. Ratio macro-/microadenoma was 54/26. In adjusted mixed method models, we found that psychopathology significantly predicts QoL in acromegaly (in models including the variables age, gender, disease duration, tumor size, basal hormone levels, relevant treatment modalities, and relevant comorbidities), with a higher degree of psychopathology indicating a lower QoL (depression vs. AcroQoL: $B=-1.175, p<0.001$, depression vs. SF-36: $B=-1.648, p<0.001$, anxiety vs. AcroQoL: $B=-0.399, p<0.001$, anxiety vs. SF-36: $B=-0.661, p<0.001)$. The explained variances demonstrate superiority of psychopathology over biochemical control and other variables in predicting QoL in our models.

Discussion: Superiority of psychopathology over biochemical control calls for a more extensive approach regarding diagnosing depression and anxiety in pituitary adenomas to improve QoL. Depressive symptoms and anxiety are modifiable factors that might provide valuable targets for possible future treatment interventions.

Keywords: acromegaly, anxiety, biochemical control, depression, pituitary adenomas, quality of life

\section{INTRODUCTION}

Objectives for health outcomes include reduction of mortality, morbidity, and the improvement of Quality of Life (QoL) (1).

However, in patients with pituitary adenomas, such as acromegaly, this third treatment goal remains often unfulfilled as they report to have a markedly reduced QoL, which often persists under biochemical control/remission (2-7).

Various factors have been suggested to be associated with reduced QoL in pituitary disease, particularly acromegaly; however, there is no clear consensus in this regard.

The current consensus criteria for cure and remission of acromegaly are based on biochemical variables, i.e., normalization of elevated hormonal levels of the biomarkers growth hormone (GH) and/or insulin like growth factor-1 (IGF-1) (8-10). However, the definition of such a "remission" remains insufficient with regard to absolute recovery: a drawback of a purely biochemical approach is that there are strong indications that biochemical control does not necessarily provide complete "cure" in patients' view, since their health-related QoL remains reduced in most patients with acromegaly.

However, there is no consensus on the value of these contributing factors. For instance, several articles reported biochemical control to have no significant association with reduced QoL (1113), whereas other articles report exactly the opposite (14-16), indicating a clear need for elucidation.

Psychopathological variables are candidate modifiable factors to link pituitary disease, especially acromegaly, to a lower healthrelated QoL. On the one hand, acromegaly is reported to be associated with neuropsychiatric comorbidities such as depressive symptoms $(17)$ and anxiety $(5,18,19)$. On the other hand, there is a clear association between psychopathology and perceived QoL (20-22).

The aim of this study was therefore to test the predictive impact of psychopathology (depressive symptoms and anxiety) on health-related QoL in acromegalic patients.

For this purpose, a theoretical model (23) was applied on acromegaly and tested in two primary data sets: (a) a 
cross-sectional cohort of 80 acromegalic patients, which was (b) subsequently validated in the longitudinal cohort of the same patients.

\section{MATERIALS AND METHODS STUDY DESIGN}

This is a prospective cohort study including two analytic parts: a cross-sectional and prospective evaluation. For design and recruitment of the initial cross-sectional cohort, see previous publications from our group $(18,19)$. Six years after the cross-sectional evaluation (baseline), a longitudinal evaluation was performed in which the same patients were recontacted and asked to participate using the same diagnostic instruments.

\section{STUDY PARTICIPANTS}

For the cross-sectional analyses, 80 acromegalic patients (response rate $56 \%$ ) were included. Patients were recruited at the Endocrine Outpatient Clinic at the Max Planck Institute of Psychiatry and the Medizinische Klinik und Poliklinik IV, Ludwig-MaximiliansUniversität Munich.

For the longitudinal analyses, patients were recontacted and recruited accordingly. At both timepoints, patients were contacted by a letter regarding the aim and design of the study. A further request for participation was issued via telephone for initial non-responders.

Thirty-six acromegalic patients (response rate 45\%), were included at the follow-up timepoint.

The project was approved by the medical ethics committee of the Ludwig-Maximilians-Universität Munich; all patients gave their written informed consent.

\section{MEASUREMENT INSTRUMENTS Clinical characteristics}

Patients were given questionnaires with standardized psychometric instruments, which allowed assessment of disease-related variables, therapy history, symptoms, tumor characteristics, comorbidities and current complaints, and evaluation of psychopathological symptoms. Patients were seen either at the Max Planck Institute for Psychiatry or at the Ludwig-MaximiliansUniversität Munich for a standardized clinical assessment, which included a physical examination and laboratory analyses. Additional information was retrieved from the patient files if necessary.

\section{Laboratory measurements}

Biochemical control (dichotomous classification) was based on a single serum sample of patients with confirmed disease. Biochemical control of acromegaly was defined as (1) GH levels $<1 \mu \mathrm{g} / \mathrm{l}$ during a glucose-tolerance test over $2 \mathrm{~h}$ and (2) IGF-1 levels within 2 SD of an age- and gender-adjusted standardized sample (8).

Pituitary function was routinely assessed in all patients on a yearly basis, with basal fasting measurements of IGF-1, thyroid stimulating hormone (TSH), free thyroxine, total triiodothyronine, luteinizing hormone ( $\mathrm{LH})$, follicle-stimulating hormone (FSH), prolactin, and testosterone (men) or estradiol (female). Moreover, stimulation tests were administered including short $\mathrm{ACTH}$ test, GHRH/arginine test, and insulin hypoglycemia test, if indicated. All patients were studied under optimal replacement therapy (24).

\section{Neuropsychiatric assessment}

Quality of Life was measured using the specifically designed instrument AcroQoL (range 0-110) (25), and the general instrument SF-36 (range 0-100) $(26,27)$. All QoL instruments were arranged to have higher scores reflecting a better QoL.

The following neuropsychiatric variables were assessed: depressive symptoms [Becks Depression Inventory (BDI) (28), range 063] and anxiety [State-Trait Anxiety Inventory (STAI) (29), range 40-160]. Neuropsychiatric scoring-instruments were arranged to have higher scores reflect greater disability.

All questionnaires were self-completed.

\section{STATISTICAL ANALYSIS}

All analyses were performed with the Statistical Package for the Social Sciences 20.0 Software (SPSS 20.0).

\section{DESCRIPTIVE ANALYSES}

Differences between biochemically controlled and uncontrolled patients for demographic variables were analyzed using $\chi^{2}$-tests and independent samples $t$-tests. Significance was set at the 0.05 level.

\section{STATISTICAL MODELS}

Six-Block linear regression analyses were carried out to assess the contribution of different variables to the outcome QoL. Block 1 contained age and gender, block 2 contained tumor

Table 1 | Demographic variables according to disease control.

\begin{tabular}{|c|c|c|c|}
\hline & Uncontrolled & Controlled & $P^{*}$ \\
\hline \multirow[t]{2}{*}{ Subjects at baseline $(N)$} & \multicolumn{2}{|c|}{80} & \\
\hline & 31 & 49 & \\
\hline \multirow[t]{2}{*}{ Subjects at follow-up } & \multicolumn{2}{|c|}{36} & \\
\hline & 15 & 21 & \\
\hline \multirow[t]{2}{*}{ Follow-up time (years) ${ }^{a}$} & \multicolumn{2}{|c|}{$7.1 \pm 0.7$} & \\
\hline & $7.1 \pm 0.5$ & $7.1 \pm 0.8$ & 1.000 \\
\hline \multirow[t]{2}{*}{ Age $\left(\right.$ years) ${ }^{a}$} & \multicolumn{2}{|c|}{$54.7 \pm 12.3$} & \\
\hline & $51.9 \pm 14.0$ & $56.7 \pm 10.8$ & 0.088 \\
\hline \multirow[t]{2}{*}{ Disease duration (years) ${ }^{a}$} & \multicolumn{2}{|c|}{$10.8 \pm 10.0$} & \\
\hline & $10.6 \pm 10.6$ & $11.2 \pm 9.6$ & 0.822 \\
\hline \multirow[t]{2}{*}{$\%$ Male $^{b}$} & \multicolumn{2}{|c|}{$46.3(37)$} & \\
\hline & $54.8(17)$ & $40.8(20)$ & 0.220 \\
\hline \multirow[t]{2}{*}{$\%$ Macroadenoma } & \multicolumn{2}{|c|}{$68.8(55)$} & \\
\hline & $80.6(25)$ & $61.2(30)$ & 0.068 \\
\hline \multirow[t]{2}{*}{ Basal GH ${ }^{c}$} & \multicolumn{2}{|c|}{$2.8 \pm 5.0$} & \\
\hline & $5.3 \pm 7.1$ & $1.1 \pm 0.9$ & 0.003 \\
\hline \multicolumn{4}{|c|}{${ }^{*} p$-Values computed using independent $t$-tests, chi square tests for the variables } \\
\hline \multicolumn{4}{|c|}{$\%$ Male and \% Macroadenoma. } \\
\hline \multicolumn{4}{|l|}{${ }^{a}$ Mean $\pm S D$} \\
\hline${ }^{b} \%(N)$. & & & \\
\hline
\end{tabular}


Table 2 | Association of psychopathology/biochemical control and QoL at baseline.

\begin{tabular}{|c|c|c|c|c|c|}
\hline Disease (scale) & Variable & $B$ (SE) & $p^{*}$ & $\Delta R^{2}$ after correction ${ }^{a}$ & Model $R^{2}$ \\
\hline \multirow[t]{3}{*}{ Acromegaly (AcroQoL) ${ }^{b}$} & Depressive symptoms & $-1.175(0.170)$ & $<0.001$ & 0.256 & 0.688 \\
\hline & Biochemical control & -1.157 (3.009) & 0.702 & 0.001 & \\
\hline & Biochemical control & $-0.546(3.497)$ & 0.876 & $<0.001$ & \\
\hline \multirow[t]{2}{*}{ Acromegaly (SF-36) ${ }^{\mathrm{C}}$} & Depressive symptoms & $-1.648(0.256)$ & $<0.001$ & 0.279 & 0.618 \\
\hline & Biochemical control & $3.126(4.614)$ & 0.501 & 0.003 & \\
\hline
\end{tabular}

${ }^{*} p$-Values were computed using linear regression.

${ }^{a}$ All models carried a correction for age, gender, disease duration, basal hormone levels and tumor size.

Additional correction for:

${ }^{b}$ radiation, pathological glucose intolerance and arthralgia,

cradiation, arthralgia.

Bold font marks those results with statistical significance.

size (dichotomous: macro- vs. microadenoma), basal GH levels, and disease duration, block 3 contained treatment types [dichotomous: surgery, radiation therapy, octreotide, lanreotide, dopamine-agonists (bromocriptin, lisuride, cabergoline, quinagolide), pegvisomant], block 4 contained comorbidities (dichotomous: arrhythmia, cardiomyopathy, cerebrovascular diseases, arterial hypertension, coronary artery disease, history of myocardial infarction, arthralgia, arthropathy, carpal tunnel syndrome, diabetes mellitus type 2, pathological glucose-tolerance, pituitary insufficiency, sleep apnea, lung diseases, cancer), and block 5 contained the psychopathological variables (depressive symptoms, anxiety). Separate analyses were carried out for depressive symptoms and anxiety (block 5) due to large correlations (Pearson's $r=0.713, p<0.001$ ). Block 6 contained the variable biochemical control as a predictor. A forced entry method was used for block 1,2,5, and 6 as we deemed inclusion of these variables, a basic requirement for our model. A stepwise forward likelihood ratio method was used for blocks 3 and 4 to include only those predictors that carried significant predictive value. The likelihood ratio method is preferable over the other stepwise methods (30).

For the longitudinal analyses to determine predictors of longterm QoL, linear mixed-effect models with a first-order autoregressive covariance matrix for repeated effects were used. Linear mixed-effects models allow a flexible length of follow-up for separate patients and account for within-patient variations (31, 32). Separate regression coefficients and intercepts were created for each individual patient. To investigate the influence of psychopathology on progression of QoL, the interaction between time and depressive symptoms/anxiety was investigated. A similar approach was taken to investigate if biochemically controlled patients progress differently throughout time in terms of QoL than their uncontrolled counterparts by investigating an interaction between time and biochemical control. Variables that yielded a significant contribution in the baseline model were implemented as factors/covariates in all longitudinal models, as well as age, gender, disease duration, and basal hormonal levels, to account for confounding. Normality was confirmed by examining normal probability plots. Significance was set at the 0.05 level.

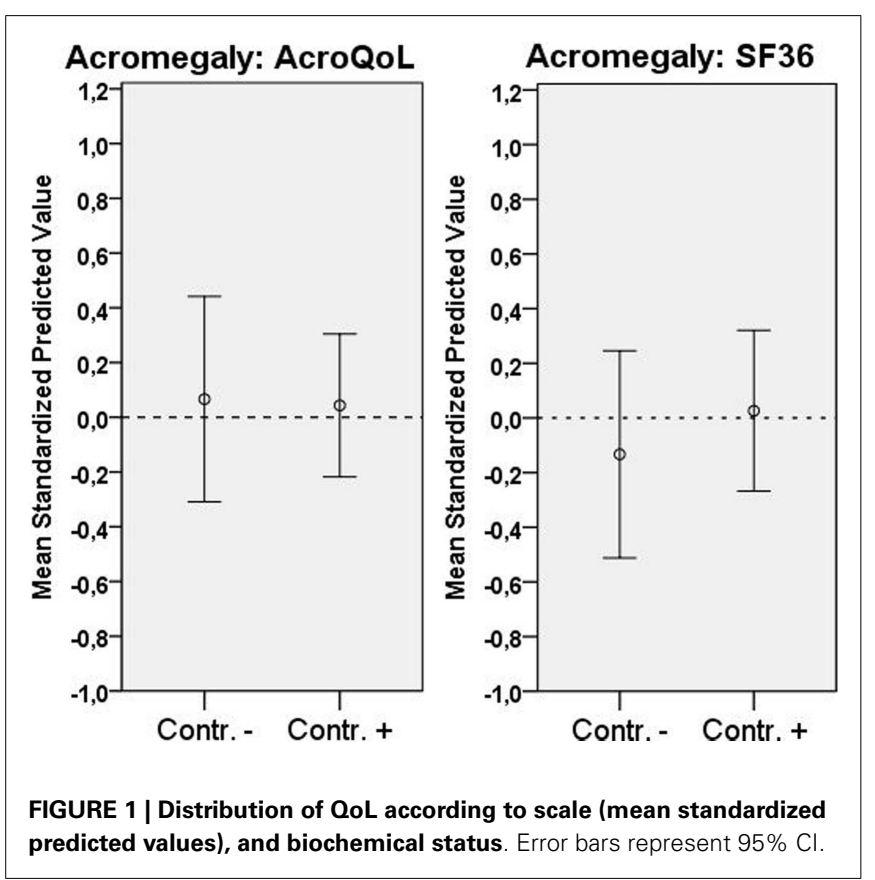

\section{MISSING VALUES}

If $15 \%$ or more of the data from a questionnaire or scale was missing, data from that variable was excluded from analysis. Remaining missing values were filled in according to the corresponding scoring instructions or by using the median from the separate items if the scoring instructions lacked a suggestion for dealing with missing values. An exception was made for the covariate biochemical control; missing data in this domain resulted in exclusion from analysis for that patient.

\section{RESULTS}

\section{DEMOGRAPHIC AND CLINICAL CHARACTERISTICS}

Mean age for the total acromegalic cohort was $54.7 \pm 12.3$ years with an average disease duration of $10.8 \pm 10.0$ years. Fifty-four patients had a macroadenoma, 26 patients had a microadenoma. 

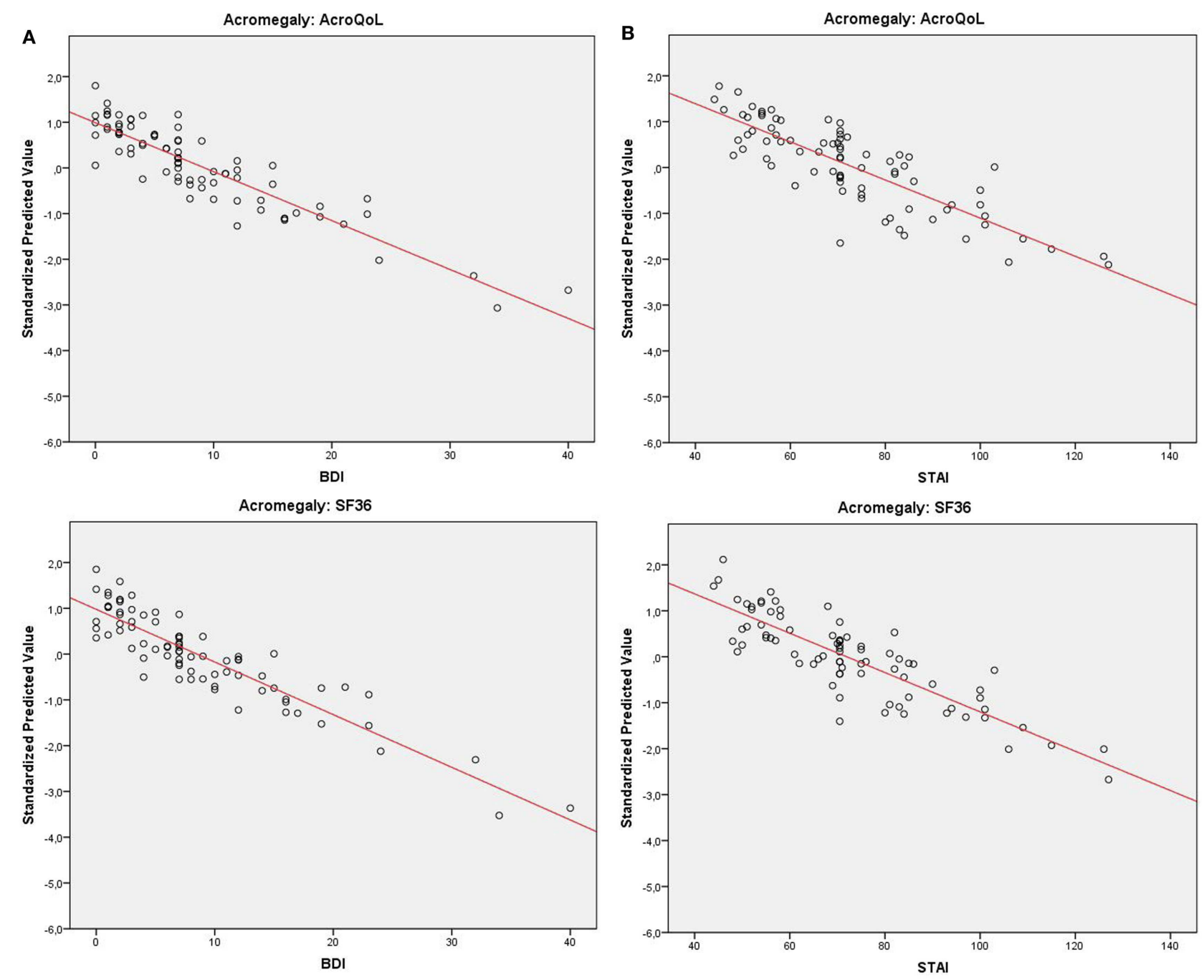

FIGURE 2 | (A) Distribution of QoL in acromegaly (standardized predicted values) relative to depressive symptoms with fitted trend-line. (B) Distribution of QoL in acromegaly (standardized predicted values) relative to anxiety with fitted trend-line.

At baseline, 31 patients were biochemically uncontrolled, and 49 patients were biochemically controlled. Mean basal hormonal level was $2.8 \pm 5.0 \mu \mathrm{g} / \mathrm{l}$ for $\mathrm{GH}$ and $214.2 \pm 161.2 \mathrm{nmol} / \mathrm{l}$, for IGF-1.

For the follow-up analyses, 36 patients participated, mean follow-up time was $7.1 \pm 0.7$ years - 15 patients remained uncontrolled, whereas 21 patients were biochemically controlled at follow-up. Demographic and clinical characteristics (crosssectional and longitudinal) are shown in Table 1.

\section{ASSOCIATION BETWEEN PSYCHOPATHOLOGY/BIOCHEMICAL CONTROL AND QOL AT BASELINE}

At baseline, our analyses demonstrate that depressive symptoms significantly predicted QoL measured by AcroQoL $(p<0.001)$ and SF-36 $(p<0.001)$ in acromegaly in a model including age, gender, disease duration, basal GH levels, tumor size, and possible treatment modalities and comorbidities as covariates. Negative coefficients reflect a greater amount of depressive symptoms to be indicative of a greater impairment of QoL. The amount of variance explained $\left(\Delta R^{2}\right)$ by depressive symptoms is 0.261 for the AcroQoL and 0.285 for the SF-36, which was the highest variance among all covariates in models explaining a variance $\left(R^{2}\right)$ of 0.637 (AcroQoL) and 0.577 (SF-36).

Similarly, results demonstrate anxiety to be significantly predictive for the AcroQoL $(p<0.001)$ and the SF-36 $(p<0.001)$ in acromegaly. Negative coefficients reflect a greater amount of anxiety to be indicative of a greater impairment of QoL. $\Delta R^{2}$ is 0.149 for AcroQoL and 0.256 for SF-36 in models with an $R^{2}$ of 0.505 (AcroQoL) and 0.543 (SF-36).

Biochemical control was not significantly associated with QoL in acromegaly.

Coefficients, $p$-values, and explained variances $\left(R^{2}\right)$ are shown in Table 2, Figure 1 (biochemical control), and Figure 2 (psychopathology). 


\section{ASSOCIATION BETWEEN PSYCHOPATHOLOGY/BIOCHEMICAL CONTROL AND OOL AT FOLLOW-UP}

At follow-up (longitudinal analyses), results demonstrate depressive symptoms to be significantly predictive of QoL measured by AcroQoL $(p<0.001)$ and SF-36 $(p=0.001)$ in acromegaly in a similar model with age, gender, disease duration, basal GH levels, tumor size, and possible treatment modalities and comorbidities as covariates. Similarly, results demonstrate anxiety to be predictive of QoL measured by AcroQoL $(p<0.001)$ and SF-36 $(p<0.001)$ in acromegaly. Negative estimates reflect a greater amount of depressive symptoms/anxiety to be indicative of impaired QoL.

Biochemical control was otherwise not significantly predictive of QoL in other analyses.

Estimates and $p$-values are shown in Table 3.

Table 3 | Association of psychopathology/biochemical control and QoL at follow-up.

\begin{tabular}{llrr}
\hline Disease (scale) & Variable & Estimate (SE) & \multicolumn{1}{c}{$\boldsymbol{P}^{\mathbf{*}}$} \\
\hline Acromegaly & Depressive symptoms & $-\mathbf{1 . 2 1 3}(\mathbf{0 . 1 5 4})$ & $<\mathbf{0 . 0 0 1}$ \\
(AcroQoL) $^{\mathrm{b}}$ & Biochemical control & $-1.973(2.910)$ & 0.500 \\
& Anxiety & $-\mathbf{0 . 4 0 5 ( 0 . 0 7 4 )}$ & $<\mathbf{0 . 0 0 1}$ \\
& Biochemical control & $-1.281(3.473)$ & 0.713 \\
& Depressive symptoms & $-\mathbf{1 . 6 0 1 ( 0 . 2 3 6 )}$ & $\mathbf{0 . 0 0 1}$ \\
Acromegaly $^{\text {SF-36) }}$ & Biochemical control & $2.420(4.072)$ & 0.555 \\
& Anxiety & $-\mathbf{0 . 6 6 6 ( 0 . 0 8 7 )}$ & $<\mathbf{0 . 0 0 1}$ \\
& Biochemical control & $3.647(4.471)$ & 0.418
\end{tabular}

${ }^{*} p$-Values computed using linear mixed models.

${ }^{a}$ All models carried a correction for age, gender, disease duration, basal hormone levels, and tumor size.

Additional correction for:

${ }^{b}$ radiation, pathological glucose intolerance and arthralgia,

${ }^{c}$ radiation, arthralgia.

Bold font marks those results with statistical significance.

Table 4 | Association of psychopathology/biochemical control and progression of QoL.

\begin{tabular}{llrc}
\hline Disease (scale) & Variable & Estimate (SE) & $\boldsymbol{P}^{*}$ \\
\hline Acromegaly & Depressive symptoms*time & $-0.107(0.222)$ & 0.632 \\
(AcroQoL) $^{\text {b }}$ & Biochemical control*time & $0.272(3.244)$ & 0.934 \\
& Anxiety*time & $-0.005(0.041)$ & 0.900 \\
& Biochemical control*time & $0.434(3.743)$ & 0.908 \\
& & & \\
Acromegaly & Depressive symptoms*time & $-0.121(0.335)$ & 0.922 \\
SF-36) $^{\mathrm{c}}$ & Biochemical control*time & $-1.512(4.823)$ & 0.926 \\
& Anxiety*time & $-0.052(0.047)$ & 0.274 \\
& Biochemical control*time & $-1.712(4.271)$ & 0.691 \\
\hline
\end{tabular}

${ }^{*} p$-Values computed using linear mixed models.

${ }^{a}$ All models carried a correction for age, gender, disease duration, basal hormone levels and tumor size.

Additional correction for:

${ }^{b}$ radiation, pathological glucose intolerance, and arthralgia,

cradiation, arthralgia.

\section{ASSOCIATION BETWEEN PSYCHOPATHOLOGY/BIOCHEMICAL CONTROL AND PROGRESSION OF QOL THROUGHOUT TIME}

Interaction between time and depressive symptoms, time and anxiety, and time and biochemical control was not significantly associated with QoL in acromegaly, indicating no influence of depressive symptoms, anxiety, or biochemical control on the progression of QoL throughout time. Estimates and $p$-values are shown in Table 4 and Figure 3.

\section{DISCUSSION}

The aim of this study was to analyze the relative impact of previously described predictors in relation to psychopathology on the patient-related health outcome "QoL" in acromegaly.

Since most of the known variables associated with a poor health-related QoL in acromegaly are not modifiable (such as age, gender, disease duration and tumor size), we focused on psychopathology, which would reflect a treatable component that is commonly underdiagnosed.

Although the relationship between QoL and psychopathology has been described before (20-22) in parallel to a solid recognition of reduced QoL in pituitary adenomas and acromegaly (2,

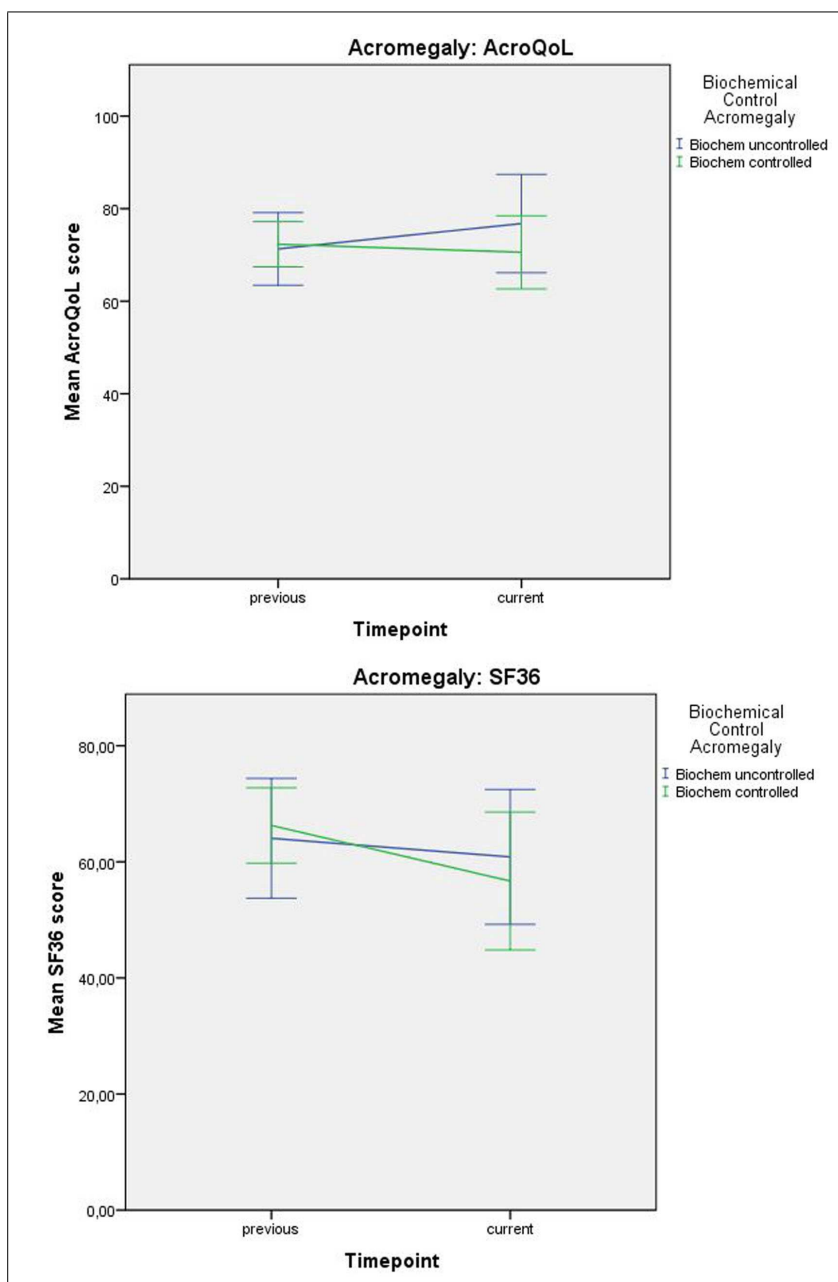

FIGURE 3 | Progression of QoL (mean values) in acromegaly relative to biochemical status. Error bars represent $95 \% \mathrm{Cl}$ 
3), we found that the marked reduction of QoL is driven dominantly by psychopathology rather than biochemical control or other factors, which is new information. A potential reason for this observation is that hormonal factors in acromegaly are not necessarily noticeable on a daily basis whereas psychopathological factors are much more dominantly present. The overbearing character of psychopathology may therefore exert a larger influence on a patient's QoL than the less obvious biochemical control.

It has been previously described that psychopathology is an independent predictor of QoL rather than a masked way of measuring QoL in pituitary patients (6). The scientific implications of our research are augmented by the World Health Organization, which has long recognized the crucial role of QoL in patientoriented clinical approaches (33). Moreover, a clear association between high QoL scores and a longer survival duration in cancer patients has been described previously (34). These results are in agreement with an earlier study that argues the importance of adding a QoL component rather than sole biochemical considerations in order to improve patient management (35). The findings that psychopathology, rather than biochemical control, drives reduced QoL based on the demonstrated explained variances complements the well-recognized reduction of QoL in pituitary adenomas and leads to our recommendation to place greater emphasis on the role of psychopathology in acromegaly.

Aside from scientific implications, key in the clinical application of this research is the finding that important predictors of reduced QoL are depressive symptoms and anxiety, which are essentially modifiable predictors. A more complex treatment strategy including a more extensive psychopathological evaluation and therapy may be an attractive possibility to improve patient management in pituitary adenomas and especially acromegaly.

\section{STRENGTHS AND LIMITATIONS}

Strengths of our study are the longitudinal design, the two-center approach, the large amount of potential confounders that are accounted for and the usage of validated and disease-specific questionnaires. Furthermore, our study yields new and additional information to expand on previous research and has obvious clinical relevance.

Limitations of our study as in each and every longitudinal study are the potential bias that is introduced due to a preferential "lossto-follow-up.” Reasons for this non-response were, e.g., disinterest to participate in a large questionnaire, feeling of being cured, and associated disinterest to participate in medical research, deterioration, and associated inability to fill out questionnaires or death. The reasons for non-compliance in our study were not systematically studied. Additionally, not all potential influential factors have been included in the study, e.g., no available data on antidepressant drug-usage, which may be influential on the severity of the depressive symptoms.

Future research should focus on improving the response rates and validate the observed findings in preferably larger cohorts. Systematic reviews of the literature should attest whether there are other (ideally modifiable) predictors of QoL in acromegaly aside from psychopathology to identify multiple targets for improving QoL (research in progress). Trials with modifying these variables could ultimately verify their clinical applicability (protocol submitted for ethical vote, phase 4 trial EudraCT 2014-000265-43).

\section{CONCLUSION}

Results indicate biochemical control of acromegaly to be unassociated with both generic and disease-specific QoL. Psychopathology seems to predominantly drive reduced QoL in acromegaly. Hence, we recommend scrutinous systematic screening for psychopathology leading to subsequent specific therapy in acromegaly to test the effect on improving QoL.

\section{REFERENCES}

1. Guilbert JJ. The world health report 2. Educ Health (Abingdon) (2003) 16(2):230. doi:10.1080/1357628031000116808

2. Crespo I, Santos A, Resmini E, Valassi E, Martínez-Mombían MA, Webb SM. Improving quality of life in patients with pituitary tumours. Eur Endocrinol (2013) 9(1):32-6.

3. Johnson MD, Woodburn CJ, Vance ML. Quality of life in patients with a pituitary adenoma. Pituitary (2003) 6(2):81-7. doi:10.1023/B:PITU.0000004798. 27230.ed

4. van der Klaauw AA, Biermasz NR, Hoftijzer HC, Pereira AM, Romijn JA. Previous radiotherapy negatively influences quality of life during 4 years of follow-up in patients cured from acromegaly. Clin Endocrinol (Oxf) (2008) 69(1):123-8. doi:10.1111/j.1365-2265.2007.03169.x

5. van der Klaauw AA, Kars M, Biermasz NR, Roelfsema F, Dekkers OM, Corssmit EP, et al. Disease-specific impairments in quality of life during long-term follow-up of patients with different pituitary adenomas. Clin Endocrinol (Oxf) (2008) 69(5):775-84. doi:10.1111/j.1365-2265.2008.03288.x

6. Biermasz NR, van Thiel SW, Pereira AM, Hoftijzer HC, van Hemert AM, Smit JW, et al. Decreased quality of life in patients with acromegaly despite long-term cure of growth hormone excess. J Clin Endocrinol Metab (2004) 89(11):5369-76. doi:10.1210/jc.2004-0669

7. Psaras T, Milian M, Hattermann V, Will BE, Tatagiba M, Honegger J. Predictive factors for neurocognitive function and Quality of Life after surgical treatment for Cushing's disease and acromegaly. J Endocrinol Invest (2011) 34(7):e168-77. doi: $10.3275 / 7333$

8. Giustina A, Barkan A, Casanueva FF, Cavagnini F, Frohman L, Ho K, et al. Criteria for cure of acromegaly: a consensus statement. J Clin Endocrinol Metab (2000) 85(2):526-9. doi:10.1210/jcem.85.2.6363

9. Giustina A, Chanson P, Kleinberg D, Bronstein MD, Clemmons DR, Klibanski A, et al. Expert consensus document: a consensus on the medical treatment of acromegaly. Nat Rev Endocrinol (2014) 10(4):243-8. doi:10.1038/nrendo. 2014.21

10. Melmed S, Casanueva FF, Klibanski A, Bronstein MD, Chanson P, Lamberts SW, et al. A consensus on the diagnosis and treatment of acromegaly complications. Pituitary (2013) 16(3):294-302. doi:10.1007/s11102-012-0420-x

11. Hua SC, Yan YH, Chang TC. Associations of remission status and lanreotide treatment with quality of life in patients with treated acromegaly. Eur J Endocrinol (2006) 155(6):831-7. doi:10.1530/eje.1.02292

12. T'Sjoen G, Bex M, Maiter D, Velkeniers B, Abs R. Health-related quality of life in acromegalic subjects: data from AcroBel, the Belgian registry on acromegaly. Eur J Endocrinol (2007) 157(4):411-7. doi:10.1530/EJE-07-0356

13. Matta MP, Couture E, Cazals L, Vezzosi D, Bennet A, Caron P. Impaired quality of life of patients with acromegaly: control of GH/IGF-I excess improves psychological subscale appearance. Eur J Endocrinol (2008) 158(3):305-10. doi:10.1530/EJE-07-0697

14. Ben-Shlomo A, Sheppard MC, Stephens JM, Pulgar S, Melmed S. Clinical, quality of life, and economic value of acromegaly disease control. Pituitary (2011) 14(3):284-94. doi:10.1007/s11102-011-0310-7

15. Trepp R, Everts R, Stettler C, Fischli S, Allemann S, Webb SM, et al. Assessment of quality of life in patients with uncontrolled vs. controlled acromegaly using the Acromegaly Quality of Life Questionnaire (AcroQoL). Clin Endocrinol (Oxf) (2005) 63(1):103-10. doi:10.1111/j.1365-2265.2005.02307.x

16. Paisley AN, Rowles SV, Roberts ME, Webb SM, Badia X, Prieto L, et al. Treatment of acromegaly improves quality of life, measured by AcroQol. Clin Endocrinol (Oxf) (2007) 67(3):358-62. doi:10.1111/j.1365-2265.2007.02891.x 
17. Anagnostis P, Efstathiadou ZA, Charizopoulou M, Selalmatzidou D, Karathanasi E, Poulasouchidou M, et al. Psychological profile and quality of life in patients with acromegaly in Greece. Is there any difference with other chronic diseases? Endocrine (2014) 47(2):564-71. doi:10.1007/s12020-014-0166-5

18. Sievers C, Ising M, Pfister H, Dimopoulou C, Schneider HJ, Roemmler J, et al. Personality in patients with pituitary adenomas is characterized by increased anxiety-related traits: comparison of 70 acromegalic patients with patients with non-functioning pituitary adenomas and age- and gender-matched controls. Eur J Endocrinol (2009) 160(3):367-73. doi:10.1530/EJE-08-0896

19. Sievers C, Dimopoulou C, Pfister H, Lieb R, Steffin B, Roemmler J, et al. Prevalence of mental disorders in acromegaly: a cross-sectional study in 81 acromegalic patients. Clin Endocrinol (Oxf) (2009) 71(5):691-701. doi:10.1111/j.13652265.2009.03555.x

20. Rapaport MH, Clary C, Fayyad R, Endicott J. Quality-of-life impairment in depressive and anxiety disorders. Am J Psychiatry (2005) 162(6):1171-8. doi:10.1176/appi.ajp.162.6.1171

21. Angermeyer MC, Holzinger A, Matschinger H, Stengler-Wenzke K. Depression and quality of life: results of a follow-up study. Int J Soc Psychiatry (2002) 48(3):189-99. doi:10.1177/002076402128783235

22. Mendlowicz MV, Stein MB. Quality of life in individuals with anxiety disorders. Am J Psychiatry (2000) 157(5):669-82. doi:10.1176/appi.ajp.157.5.669

23. Wilson IB, Cleary PD. Linking clinical variables with health-related quality of life. A conceptual model of patient outcomes. JAMA (1995) 273(1):59-65. doi:10.1001/jama.1995.03520250075037

24. Schneider HJ, Aimaretti G, Kreitschmann-Andermahr I, Stalla GK, Ghigo E. Hypopituitarism. Lancet (2007) 369(9571):1461-70. doi:10.1016/S01406736(07)60673-4

25. Badia X, Webb SM, Prieto L, Lara N. Acromegaly quality of life questionnaire (AcroQoL). Health Qual Life Outcomes (2004) 2:13. doi:10.1186/1477-7525-241

26. McHorney CA, Ware JE Jr., Lu JF, Sherbourne CD. The MOS 36-item ShortForm Health Survey (SF-36): III. Tests of data quality, scaling assumptions, and reliability across diverse patient groups. Med Care (1994) 32(1):40-66. doi:10.1097/00005650-199401000-00004

27. Ware JE Jr, Sherbourne CD. The MOS 36-item short-form health survey (SF-36). I. Conceptual framework and item selection. Med Care (1992) 30(6):473-83. doi:10.1097/00005650-199206000-00002

28. Whisman MA, Perez JE, Ramel W. Factor structure of the Beck Depression Inventory-Second Edition (BDI-II) in a student sample. J Clin Psychol (2000) 56(4):545-51. doi:10.1002/(SICI) 1097-4679(200004)56:4<545::AIDJCLP7>3.0.CO;2-U
29. Spielberger C. Assessment of state and trait anxiety: conceptual and methodological issues. South Psychol (1985) 2(4):6-16.

30. Field A. Discovering Statistics using SPSS. 3 ed. London: SAGE Publications Ltd (2009).

31. Morley JF, Xie SX, Hurtig HI, Stern MB, Colcher A, Horn S, et al. Genetic influences on cognitive decline in Parkinson's disease. Mov Disord (2012) 27(4):512-8. doi:10.1002/mds. 24946

32. Siderowf A, Xie SX, Hurtig H, Weintraub D, Duda J, Chen-Plotkin A, et al. CSF amyloid \{beta\} 1-42 predicts cognitive decline in Parkinson disease. Neurology (2010) 75(12):1055-61. doi:10.1212/WNL.0b013e3181f39a78

33. Kuyken W, Sartorius N, Power M, Orley J. The World Health Organization Quality of Life assessment (WHOQOL): position paper from the World Health Organization. Soc Sci Med (1995) 41(10):1403-9. doi:10.1016/0277-9536(95) 00112-K

34. Montazeri A. Quality of life data as prognostic indicators of survival in cancer patients: an overview of the literature from 1982 to 2008. Health Qual Life Outcomes (2009) 7:102. doi:10.1186/1477-7525-7-102

35. Haring R, Feng YS, Moock J, Volzke H, Dorr M, Nauck M, et al. Self-perceived quality of life predicts mortality risk better than a multi-biomarker panel, but the combination of both does best. BMC Med Res Methodol (2011) 11:103. doi:10.1186/1471-2288-11-103

Conflict of Interest Statement: The authors declare that the research was conducted in the absence of any commercial or financial relationships that could be construed as a potential conflict of interest.

Received: 17 November 2014; accepted: 10 December 2014; published online: 06 January 2015.

Citation: Geraedts VJ, Dimopoulou C, Auer M, Schopohl J, Stalla GK and Sievers $C$ (2015) Health outcomes in acromegaly: depression and anxiety are promising targets for improving reduced quality of life. Front. Endocrinol. 5:229. doi: 10.3389/fendo.2014.00229

This article was submitted to Neuroendocrine Science, a section of the journal Frontiers in Endocrinology.

Copyright (c) 2015 Geraedts, Dimopoulou, Auer, Schopohl, Stalla and Sievers. This is an open-access article distributed under the terms of the Creative Commons Attribution License (CC BY). The use, distribution or reproduction in other forums is permitted, provided the original author(s) or licensor are credited and that the original publication in this journal is cited, in accordance with accepted academic practice. No use distribution or reproduction is permitted which does not comply with these terms. 